\title{
Using random forests to model 90-day hometime in people with stroke
}

\author{
Jessalyn K. Holodinsky ${ }^{1 *}$ (D, Amy Y. X. Yu²,3, Moira K. Kapral ${ }^{2,4,5}$ and Peter C. Austinn $2,5,6$
}

\begin{abstract}
Background: Ninety-day hometime, the number of days a patient is living in the community in the first 90 after stroke, exhibits a non-normal bucket-shaped distribution, with lower and upper constraints making its analysis difficult. In this proof-of-concept study we evaluated the performance of random forests regression in the analysis of hometime.

Methods: Using administrative data we identified stroke hospitalizations between 2010 and 2017 in Ontario, Canada. We used random forests regression to predict 90-day hometime using 15 covariates. Model accuracy was determined using the $r$-squared statistic. Variable importance in prediction and the marginal effects of each covariate were explored.

Results: We identified 75,745 eligible patients. Median 90-day hometime was 59 days (Q1: 2, Q3: 83). Random forests predicted hometime with reasonable accuracy (adjusted r-squared 0.3462); no implausible values were predicted but extreme values were predicted with low accuracy. Frailty, stroke severity, and age exhibited inverse nonlinear relationships with hometime and patients arriving by ambulance had less hometime than those who did not.

Conclusions: Random forests may be a useful method for analyzing 90-day hometime and capturing the complex non-linear relationships which exist between predictors and hometime. Future work should compare random forests to other models and focus on improving the accuracy of predictions of extreme values of hometime.
\end{abstract}

Keywords: Stroke, Hometime, Random forests

\section{Background}

Stroke is a leading cause of morbidity and mortality worldwide. Assessing patient outcome after stroke is important for clinical research and quality improvement initiatives. Post-stroke recovery is commonly determined using scales or questionnaires delivered via structured interview. There are several common scales available to measure outcomes after stroke, the most common being the modified Rankin Scale. However, scales such as this are subject to issue with rater bias, inter-observer variability, social desirability bias in self-reporting, and attrition bias [1]. Additionally, these scales require prospective

\footnotetext{
* Correspondence: jkholodi@ucalgary.ca

'Department of Clinical Neurosciences, Cumming School of Medicine, University of Calgary, 3330 Hospital Drive NW, Calgary, AB T2N4N1, Canada Full list of author information is available at the end of the article
}

evaluation by trained experts and as such are not commonly collected outside the clinical trial environment, meaning they cannot be used for population based studies nor for retrospective observational studies. Ninety-day hometime, defined as the total number of days a patient is living in the community (and not in a healthcare institution) in the first 90 days after stroke [2], is a new stroke outcome metric shown to be correlated with disability after stroke [3-7]. Hometime is objective and does not suffer from inter/intra-rater reliability issues or any issues related to self-reporting. Hometime can be obtained from administrative data, enabling population-based analyses [5]. Hometime is graded, with longer home-time being associated with higher post-stroke disability [2-6], unlike other outcomes available in administrative data such as mortality. Finally, home-time is meaningful to patients

(c) The Author(s). 2021 Open Access This article is licensed under a Creative Commons Attribution 4.0 International License, which permits use, sharing, adaptation, distribution and reproduction in any medium or format, as long as you give appropriate credit to the original author(s) and the source, provide a link to the Creative Commons licence, and indicate if changes were made. The images or other third party material in this article are included in the article's Creative Commons licence, unless indicated otherwise in a credit line to the material. If material is not included in the article's Creative Commons licence and your intended use is not permitted by statutory regulation or exceeds the permitted use, you will need to obtain permission directly from the copyright holder. To view a copy of this licence, visit http://creativecommons.org/licenses/by/4.0/ The Creative Commons Public Domain Dedication waiver (http://creativecommons.org/publicdomain/zero/1.0/) applies to the data made available in this article, unless otherwise stated in a credit line to the data. 
because they value reintegration into the community after stroke as well as policy-makers because this metric is intuitively associated with healthcare costs [8-10].

In prior studies, a substantial range of statistical methods have been used to analyze hometime including negative binomial regression, ordinal logistic regression, median regression, linear regression, Spearman rank correlation, $\mathrm{t}$-test and chi-square analyses, propensity score matching, and categorizing hometime into quartiles [3$7,11-13]$. While this diversity may be due to the individual study objectives, it may also reflect unique statistical properties of hometime, which make its analysis problematic. Indeed, typical parametric statistical methods may have limited utility for analyzing hometime because it follows a highly non-normal bucket shaped distribution with spikes at or near its lower and upper limits (by design, 90-day hometime is constrained to lie between 0 and 90) [5, 6] Further, the lower and upper limits themselves cause additional difficulty with applying traditional regression methods to predict hometime, as they may result in non-plausible estimated values, such as estimating a negative hometime or extrapolating beyond 90 days.

Given these challenges, random forests regression, a popular method from the machine learning literature, may be a more suitable method for the analysis of hometime. We aimed to study the use of random forests regression for modelling 90-day hometime in a populationbased cohort of stroke patients, and to determine the relative importance of several covariates in the prediction of hometime using random forests regression. We have focused this paper solely on random forests regression as a proof of concept illustrating the utility of random forests for hometime. We do not compare the use of random forests to other regression methods in this paper. We have structured this article in the following way: first, we describe random forests regression and its advantages for analyzing hometime. Second, we apply random forests regression to predict 90-day hometime in a populationbased cohort of stroke patients and discuss the model's performance. Third, we highlight the relative importance of several clinically relevant covariates in the prediction of hometime using this method.

\section{Random forests}

\section{Overview of random forests}

Classification and regression trees (CART) are a simple tool for prediction and classification. Unlike linear regression, CART is not based on a parametric regression model, but rather data are split along the predictor axes into groups (nodes). A node is split on the variable that results in the two resultant sub-nodes being as homogeneous as possible [14]. This process is then repeated recursively with each of the two resultant sub-nodes.
Predictors can be categorical or continuous (using a data-driven cut-off value for the split); outcomes can also be categorical or continuous. Random forests is a regression method based on the aggregation of a large number of these trees which has been shown to produce more accurate results than just a single tree [15]. A random forest is a variation of bootstrap aggregating (bagging) where several hundred trees are created from the same dataset and their results averaged. The training data for each tree is created from a bootstrapped sample of the full dataset, meaning that approximately one third of the observations will not be used in the training dataset. Each time a split is considered, a random sample of the predictors (among the full set of predictors) are chosen as candidates for the split. This allows multicollinearity to be handled as not all predictors are considered at each split [15]. Trees are grown to maximum size without pruning. The predictions for each observation obtained from each tree are averaged.

There are several advantages to this methodology. First, single trees can be prone to overfitting and are very sensitive to small changes in the training data [16]. Second, through bagging, there are data points which do not end up in the bootstrapped sample for any given tree (out-of-bag observations); this allows for a statistically efficient process where the random forest can be fit in one sequence with cross validation being performed along the way [16]. Finally, this methodology allows the model to capture complex interaction structures within the data in with relatively low bias [15].

One disadvantage is that this method does not produce regression coefficients which allow for the direct interpretation of each variable's impact on the outcome of interest [17]. However, by measuring the effect of variable permutation on the model's accuracy (measured using out-of-bag error estimation) and node homogeneity (measured using the Gini index), random forests allow for a variable importance measure to be determined for each predictor. As a result, one can tell, relative to the other predictors, each variable's importance in prediction of the outcome. We have provided more information on the procedures for assessing variable importance in the supplemental materials. There are also other model-agnostic interpretation methods, such as partial dependence, which allow for examining the marginal effects of each variable (one or two at a time) on the model's predictions.

\section{Advantages of random forests for the analysis of Hometime}

One of the biggest advantages of random forests is that they do not make any distributional assumptions about underlying data structures, meaning they can be used on data which exhibiting highly unusual distributions, such 
as those in hometime. One property of regression trees, sometimes discussed as a limitation, is that they cannot perform extrapolation. The estimates produced are constrained to averages of the observed data; meaning predictions which are less than the minimum or greater than the maximum outcome value which appears in the dataset on which the model was trained cannot be obtained [17]. In the setting of 90-day hometime, this is an advantage, as the random forest cannot produce nonplausible estimated values of hometime (those $<0$ or $>$ 90 days).

\section{Methods}

\section{Cohort identification}

Using the Canadian Institute for Health Information (CIHI) Discharge Abstract Database (DAD) we identified all patients with a main diagnosis of stroke (ischemic or intracerebral hemorrhage) admitted to an acute care hospital in Ontario between April 1, 2010 and December 31, 2017. Nonresidents of Ontario, those $<18$ or $>105$ years of age, strokes occurring in-hospital, patients discharged from the emergency department without inpatient hospitalization, patients with history of prior stroke, and patients in long-term care at baseline were excluded.

\section{Covariates}

Covariates of interest included age, sex, arrival by ambulance, stroke type, treatment with thrombolysis, stroke unit care, frailty (measured using the Hospital Frailty Risk Score, a continuous score from 0 to 99 derived from administrative data where scores $<5$ indicate low risk of frailty, scores 5-15 indicate moderate risk of frailty and scores $>15$ indicate high risk of frailty) [18], stroke severity (measured using the Passive Surveillance Stroke seVerity Indicator (PaSSV) where scores $<4$ indicate severe stroke, scores 4-8 indicate moderate stroke severity, and scores $>8$ indicates mild stroke severity) [19], rural vs. urban home location, quintile of median neighbourhood income, and the following comorbidities: atrial fibrillation, diabetes, hypertension, myocardial infarction. A 5-year lookback window was used for all comorbidities. Covariates were identified using linked data from the DAD, the Ontario Health Insurance Plan Database, the Ontario Diabetes Dataset [20, 21], the Ontario Hypertension Dataset [22, 23], the Ontario Myocardial Infarction Dataset [24], and the Canadian Census (case definitions are given in Table A.1). Patients with missing data were excluded from the analyses.

\section{Ninety-day Hometime calculation}

We calculated 90-day hometime using linked data from the following sources: DAD (inpatient hospitalization), National Ambulatory Care Reporting System (emergency department), the National Rehabilitation Reporting System (rehabilitation), the Continuing Care Reporting System (complex continuing care or long-term care), and the Ontario Registered Persons Database (mortality data). Data linkage occurred through unique encoded identifiers at ICES; these datasets have been validated extensively for research purposes [25].

For patients who survived to day 90, 90-day hometime was calculated as 90 minus the sum of length(s) of stay in ED, acute care, rehabilitation, and long-term care. For example, a patient whose sum of lengths of stay in healthcare institutions $=20$ days would have a hometime of 70 days. Patients who died prior to day 90 could still accumulate hometime days for each day spent alive and out of healthcare institutions prior to death. For example, a patient with whose sum of lengths of stay in

Table 1 Baseline characteristics of patients hospitalized with acute stroke between April 1, 2010 and December 31, 2017 and included in the study cohort

\begin{tabular}{|c|c|}
\hline Characteristic & $\begin{array}{l}\text { Complete Case Analysis } \\
\text { Cohort }(n=75,475)\end{array}$ \\
\hline Female (\%) & 47.44 \\
\hline Median Age (Q1, Q3) - years & $75(64,84)$ \\
\hline Arrived by Ambulance (\%) & 71.19 \\
\hline \multicolumn{2}{|l|}{ Stroke Type (\%) } \\
\hline Intra-cerebral hemorrhage & 12.87 \\
\hline Ischemic Stroke & 87.12 \\
\hline Diabetes (\%) & 36.61 \\
\hline Atrial Fibrillation (\%) & 14.18 \\
\hline Hypertension (\%) & 82.76 \\
\hline Myocardial Infarction (\%) & 9.19 \\
\hline \multicolumn{2}{|c|}{ Neighbourhood Income Quintile (\%) } \\
\hline Quintile 1 (lowest) & 23.60 \\
\hline Quintile 2 & 21.99 \\
\hline Quintile 3 & 19.70 \\
\hline Quintile 4 & 17.75 \\
\hline Quintile 5 (highest) & 16.96 \\
\hline \multicolumn{2}{|l|}{ Home Location (\%) } \\
\hline Rural & 12.40 \\
\hline Urban & 87.60 \\
\hline Median Frailty Score $(\mathrm{Q} 1, \mathrm{Q} 3)$ & $4.2(0.8,9.1)$ \\
\hline Median PaSSV Score ${ }^{\mathrm{b}}(\mathrm{Q} 1, \mathrm{Q} 3)$ & $7.7(6.5,8.7)$ \\
\hline Received Thrombolysis (\%) & 13.36 \\
\hline Received Stroke Unit Care (\%) & 56.01 \\
\hline
\end{tabular}

Q1: first quartile; Q3: third quartile; PaSSV: Passive Surveillance Stroke seVerity indicator

${ }^{\mathrm{a}} \mathrm{A}$ continuous score ranging from 0 to 99 where scores $<5$ indicate low risk of frailty, scores from 5 to 15 indicate intermediate risk of frailty, and scores $>15$ indicate high risk of frailty [18]

${ }^{\mathrm{b}} \mathrm{A}$ continuous score where $<4$ indicates severe stroke, 4-8 indicates moderate stroke severity, and $>8$ indicates mild stroke severity [19] 

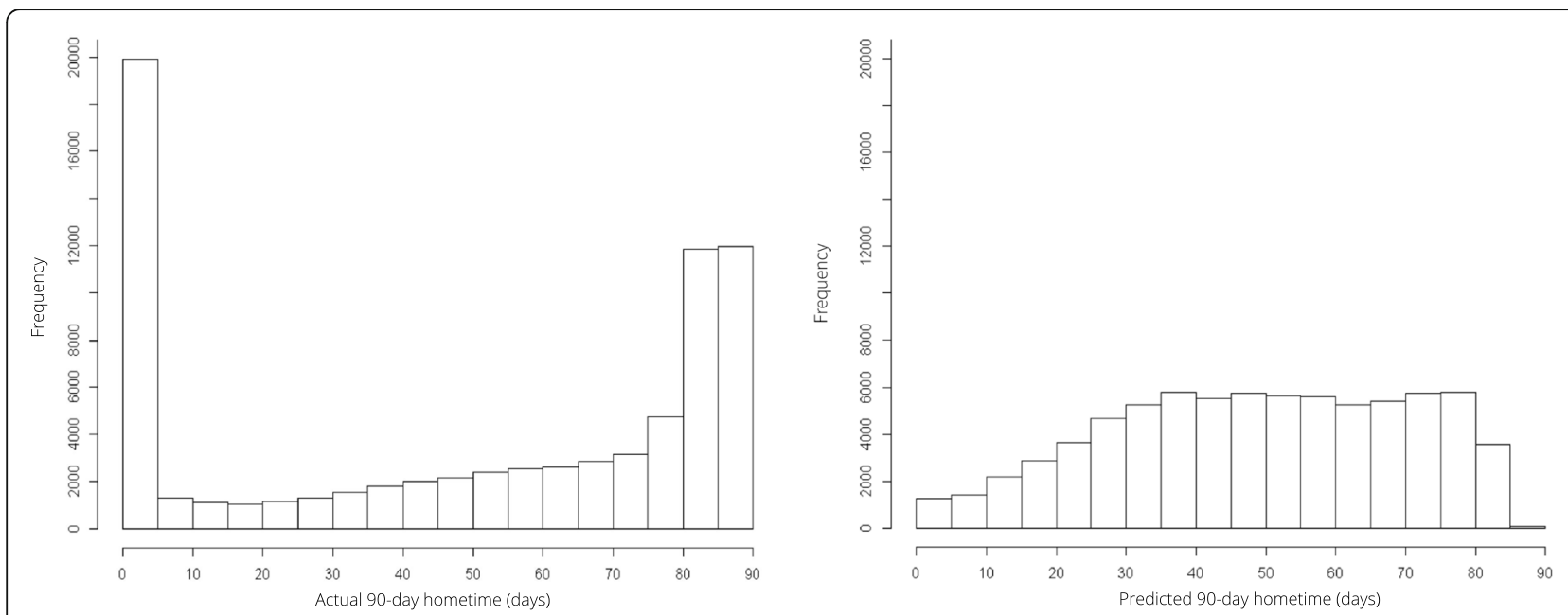

Fig. 1 Left: Histogram of 90-day hometime across the cohort of 75,475 stroke patients. Right: Histogram of predicted 90-day hometime across 75,475 patients using a random forests model with 15 clinically relevant covariates

healthcare institutions $=20$ days and died on day 70 would have a hometime of 50 days. Patients who died during the index admission have, by definition, hometime of 0 days. Hometime accumulation does not have to be continuous. For example, a patient with an acute care admission who was discharged to home and then re-admitted within 90 days of index event would have both admission lengths of stay subtracted for the 90-day hometime calculation.

\section{Statistical methods}

We used random forests regression to model 90-day hometime. A random forest consisting of 500 trees was grown, using $\mathrm{p} / 3$ candidate predictors at each split (where $\mathrm{p}=$ total number of predictors) in accordance with recommendations made by Breiman [15]. All trees were grown using a minimum node size of 5 and no restrictions on tree depth or number of terminal nodes were imposed. Model fit was assessed using adjusted Rsquared.

Using both out-of-bag error estimation and node homogeneity, the relative importance of each co-variate in predicting hometime was determined. The marginal effects that each co-variate had on the predicted outcome were illustrated using partial dependence plots. These plots show how predicted values partially depend on the values of one or more co-variates. These graphs plot the change in average predicted outcome value as a co-variate is varied over its marginal distribution [26]. These plots are post-hoc methods of model interpretation, they do not reveal the inner workings of the model, but rather reveal how the model behaves as a

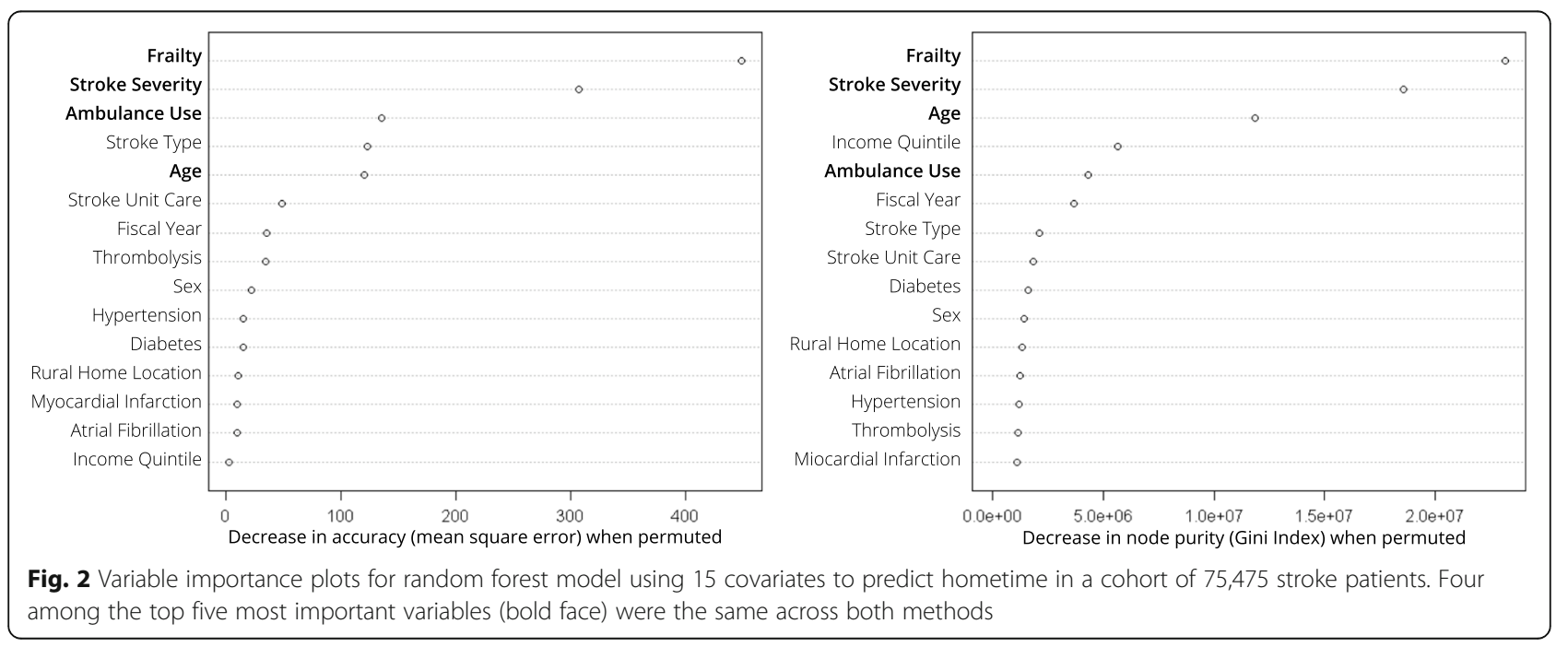


result of changing inputs. One-way partial dependence plots were generated for each co-variate. Two-way partial dependence plots were generated to depict the interaction between pairs of variables that displayed high importance for hometime. All analyses were performed using R (v3.3.0).

\section{Ethics and data availability statement}

This study was approved by the Sunnybrook Health Sciences Centre Research Ethics Board. The use of data in this project was authorized under section 45 of Ontario's Personal Health Information Protection Act. The data sets used for this study were held securely in a linked, de-identified form and analyzed at ICES. While data sharing agreements prohibit ICES from making the data set publicly available, access may be granted to those who meet pre-specified criteria for confidential access, available at www.ices.on.ca/DAS.

\section{Results}

\section{Patient characteristics}

From 109,842 acute admissions for stroke, we identified a cohort of 75,475 patients with complete data who met all inclusion criteria. The cohort selection flow chart is presented in Figure A1. We removed 202 observations with small cell counts upon cross tabulation of baseline characteristics to avoid potential re-identification of individuals as per ICES policy; aggregate demographics of these patients are given in Table A.2. Baseline characteristics of the final cohort are given in Table 1. At Day 90, $68.54 \%$ of patients were home and $17.49 \%$ of patients had died. The distribution of 90-day hometime across the entire cohort of patients is displayed in Fig. 1. The median 90-day hometime across the cohort was 59 days (Q1: 2, Q3: 83). The pairwise correlation between all covariates is given in Table A.3. Some of the predictors exhibited moderate correlation with the highest magnitude being between PaSSV score and admission via ambulance $(\rho=-0.45)$; however, as random forests regression is robust to multicollinearity all variables were included as candidates in the model.

\section{Using random forests regression to predict 90-day Hometime}

The random forests model predicted 90-day hometime with reasonable accuracy (adjusted $r$-squared $=0.3462$ ). The distribution of predicted hometime across the cohort is displayed in Fig. 1. Extreme values of hometime, both low and high, were predicted with the least accuracy. Low hometime values were systematically overestimated and high hometime values were systematically under-estimated (Figure A.2). All predicted values for hometime were plausible (minimum: 0 days; maximum: 87.39 days).

\section{Interpretation of random forests model}

Whether determining variable importance using model accuracy (out-of-bag error estimation) or node purity (Gini index), four of the top five ranked variables were the same: frailty, stroke severity, age, and ambulance use (Fig. 2). The

Table 2 Marginal estimate of hometime for variables with lower relative importance on predicted hometime

\begin{tabular}{|c|c|}
\hline Variable & Predicted 90-day hometime (days) \\
\hline \multicolumn{2}{|l|}{ Sex } \\
\hline Female & 48.8 \\
\hline Male & 48.7 \\
\hline \multicolumn{2}{|l|}{ Stroke Type } \\
\hline Intra-cerebral Hemorrhage & 40.0 \\
\hline Ischemic Stroke & 50.0 \\
\hline \multicolumn{2}{|l|}{ Diabetes } \\
\hline Yes & 47.7 \\
\hline No & 49.3 \\
\hline \multicolumn{2}{|l|}{ Atrial Fibrillation } \\
\hline Yes & 48.5 \\
\hline No & 48.8 \\
\hline \multicolumn{2}{|l|}{ Hypertension } \\
\hline Yes & 48.8 \\
\hline No & 48.3 \\
\hline \multicolumn{2}{|l|}{ Myocardial Infarction } \\
\hline Yes & 49.3 \\
\hline No & 48.7 \\
\hline \multicolumn{2}{|c|}{ Neighbourhood Income Quintile } \\
\hline Quintile 1 (lowest) & 47.9 \\
\hline Quintile 2 & 48.6 \\
\hline Quintile 3 & 49.2 \\
\hline Quintile 4 & 49.0 \\
\hline Quintile 5 (highest) & 49.2 \\
\hline \multicolumn{2}{|l|}{ Home Location } \\
\hline Rural & 47.8 \\
\hline Urban & 49.0 \\
\hline \multicolumn{2}{|l|}{ Received Thrombolysis } \\
\hline Yes & 48.5 \\
\hline No & 48.5 \\
\hline \multicolumn{2}{|l|}{ Received Stroke Unit Care } \\
\hline Yes & 49.7 \\
\hline No & 47.5 \\
\hline \multicolumn{2}{|l|}{ Fiscal Year Group } \\
\hline 2010-2011 & 45.4 \\
\hline $2012-2013$ & 46.8 \\
\hline 2014-2015 & 49.6 \\
\hline 2016-2017 & 51.1 \\
\hline
\end{tabular}


two top predictors, frailty and stroke severity, were the same for both methods of ranking variable importance and on a relative scale these variables were far more important than the other 13 covariates in predicting hometime.

\section{Influence of individual covariates on Hometime predictions}

Using both one and two-way partial dependence plots, we examined the relationships between the four co-variates ranked of high importance in predicting hometime. These partial dependence plots are interpreted as the relationship between the predictor variable(s) and 90-day hometime after averaging out the effects of all other predictors. The partial dependence estimates of the other 11 variables of relatively lower importance are summarized in Table 2.

Frailty and stroke severity were the top predictors of hometime, and the associations were non-linear. For patients with low or moderate risk of frailty (scores $\leq 15$ ), as frailty increased predicted hometime decreased; however, for patients at high risk of frailty (scores >15), there was little change in predicted hometime as frailty score increased (Fig. 3). Predicted hometime increased as stroke severity decreased, but there was less variability in predicted hometime for those with high or low stroke severity compared to those with moderate stroke severity (Fig. 3). There was an interaction between frailty and stroke severity; the rapid decrease in hometime with increasing frailty was only seen when stroke severity was low (Fig. 4). For higher stroke severity, estimated hometime remained relatively constant regardless of frailty.

Patients who arrived by ambulance had lower predicted hometime than those who did not (45.9 vs. 53.1 days) (Fig. 3). Arrival by ambulance did not change the nature of the association between hometime and frailty or stroke severity, but it created a

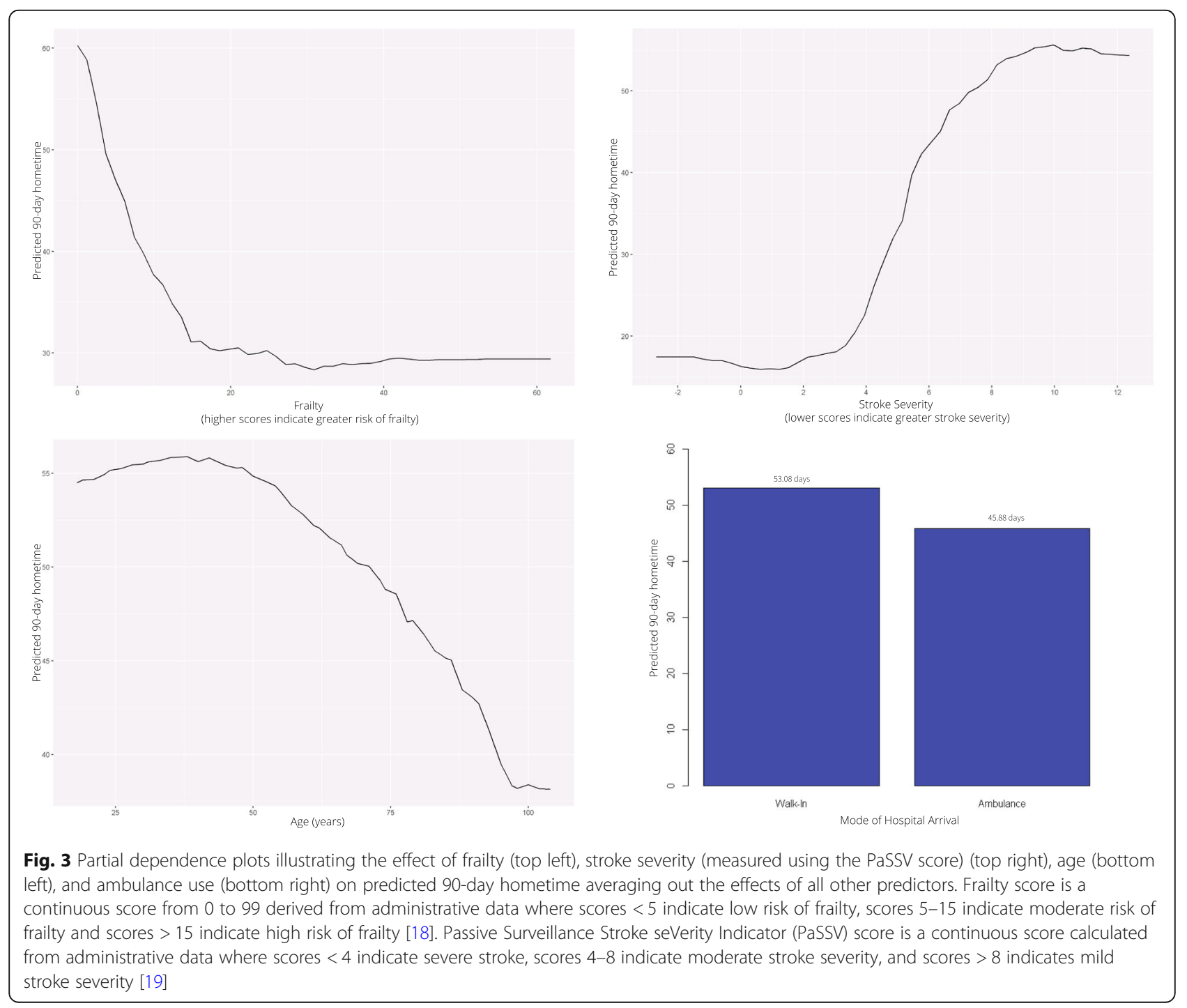




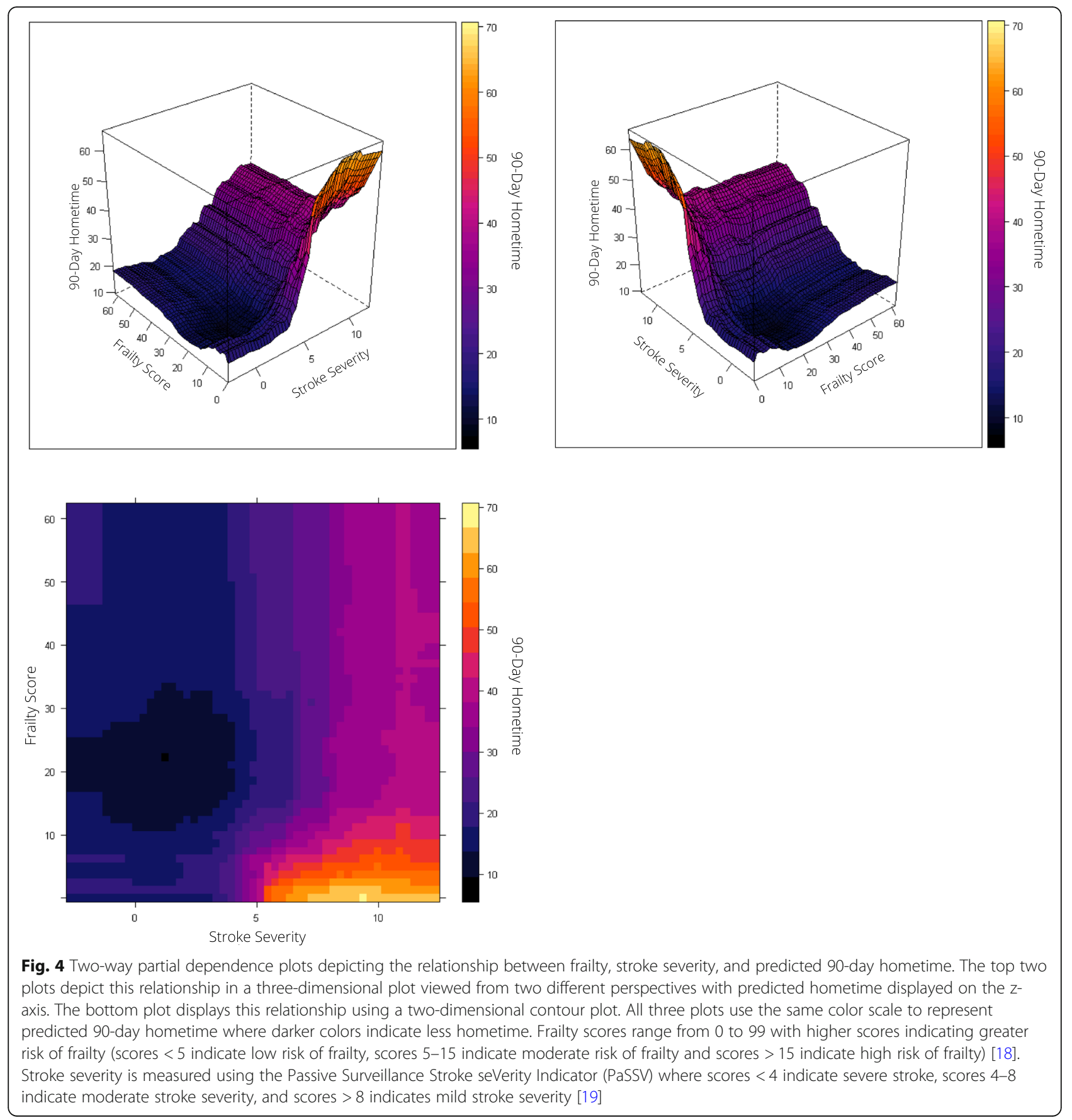

downward shift as patients arriving by ambulance overall had less predicted hometime than those who did not (Fig. 5).

Age displayed a non-linear relationship with hometime, with predicted hometime decreasing with increasing age, especially beyond age 45 (Fig. 3). The rapid decrease and then plateau in hometime as frailty increased held true across all ages (Fig. 6). The S-shaped relationship between hometime and stroke severity also persisted across all ages (Fig. 7). Patients presenting via ambulance had less hometime than those who did not across all ages, but the difference in predicted hometime between the two groups increased with age (Fig. 4).

\section{Discussion}

We found that a random forests regression model predicts hometime with reasonable accuracy without predicting implausible values. The random forests model allowed for the capturing and describing complex non- 


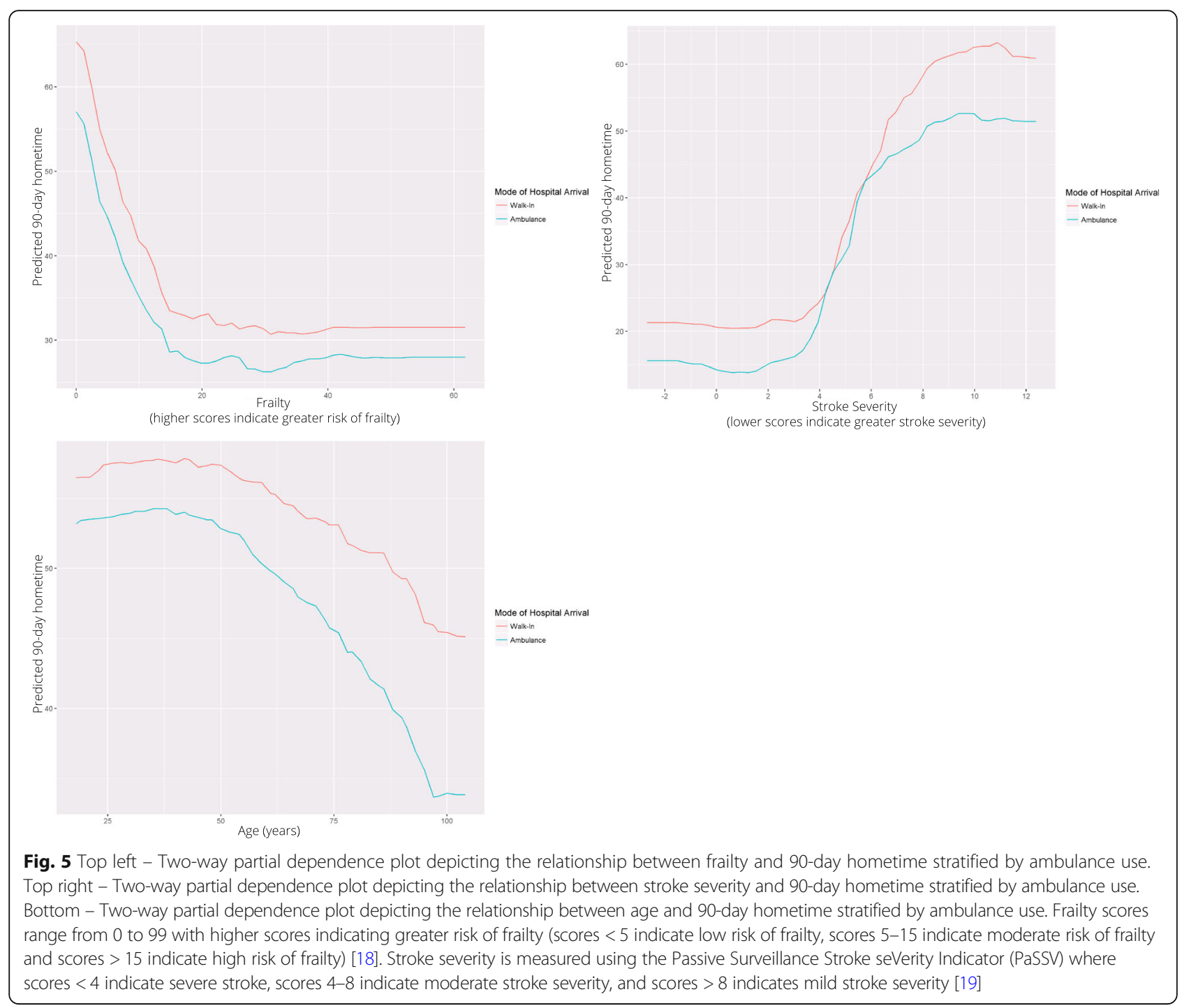

linear relationships between predictors and hometime, such as for frailty and stroke severity.

However, patients with extreme values of hometime were systematically under predicted, especially those with 0-hometime. This could be because there are two distinct groups of patients with hometime of 0 days: 1 ) those who did not survive the initial stroke admission and 2) those who survived with severe disability and remained institutionalized for the full duration of the 90 days. The characteristics of these two groups may be different and using a single model to predict these outcomes may not be ideal. Interestingly, the model also systematically under predicted hometime values for patients with high hometime. Unlike 0-hometime, high hometime only has one interpretation, that the patient was sufficiently well for early discharge to home. Another potential reason for the suboptimal prediction of the extreme values of hometime is that our set of potential covariates did not include variables which could be associated with both going home quickly and not returning home at all, such as marital status, living situation, lifestyle factors, social support, and indicators of quality of care, as these are not available in administrative data.

We found that the most important variables for predicting hometime were frailty, stroke severity, age, and ambulance use. Our findings are consistent with prior work showing that frailty [27], stroke severity, [12, 13] and age $[6,12,13]$ are associated with disability after stroke, but the association between these variables and hometime specifically is not yet well understood.

Our findings of patient location (rural vs. urban) being relatively unimportant was consistent with previous literature $[6,12]$. We found that patients with intracerebral hemorrhage had 10.0 fewer days of hometime than patients with ischemic stroke, also consistent with previous 


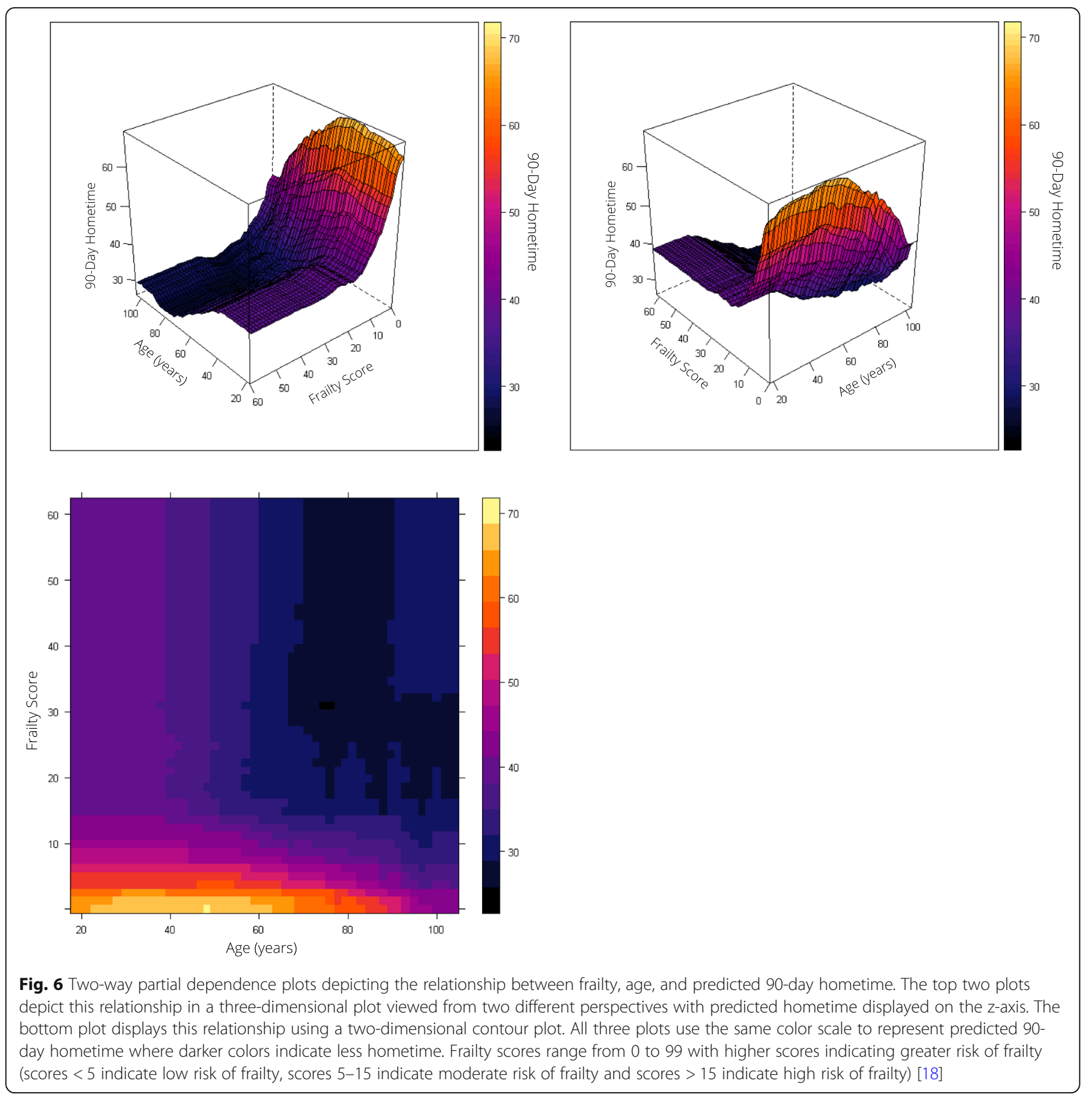

literature [6, 13]. Sex was not associated with hometime, which has been previously reported by some studies [5] but not others $[6,12]$. We did not see a difference in hometime based on thrombolysis use in this study. Prior work has shown patients receiving thrombolysis have increased hometime [3]; however, this previous study focused on patients with acute ischemic stroke who were eligible for thrombolysis whereas our study included hemorrhagic stroke patients and ischemic stroke patients who may not have been eligible for thrombolysis. Individual vascular comorbidities (atrial fibrillation, diabetes, myocardial infarction, hypertension) were not associated with hometime, suggesting that multi-morbidity, as captured by the frailty score, is likely more important in predicting outcomes after stroke than any specific comorbidity. This is consistent with our understanding of the effects of multi-morbidity on stroke outcomes $[28,29]$.

There are limitations to using random forests. Random forests are complex, consisting of hundreds of regression trees. This means that 1) a large amount of computation power and time are needed to generate them, and 2) they don't produce readily interpretable coefficients like those produced in linear regression or other parametric 


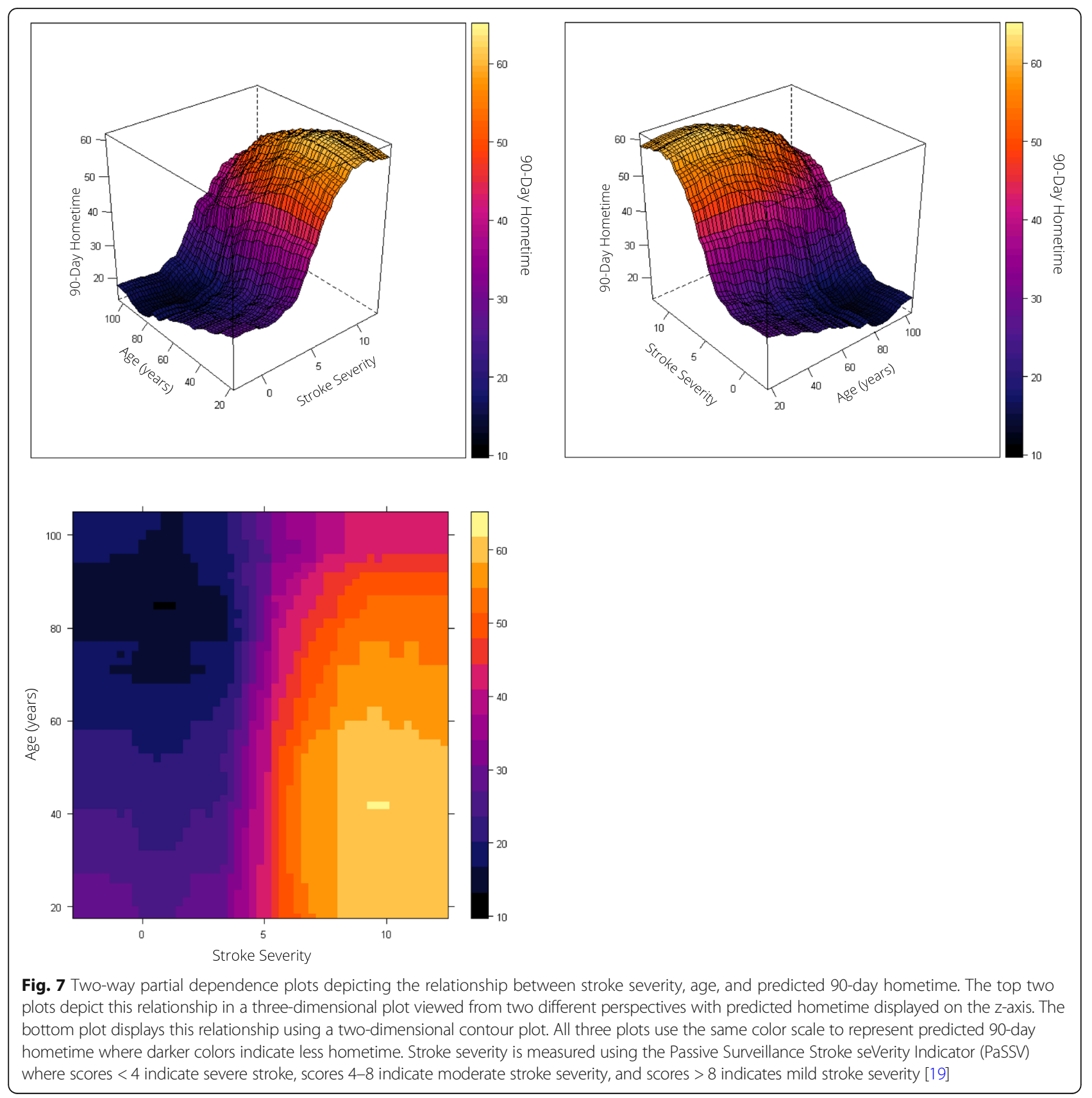

models. We have used variable importance and partial dependence plots to assist in model interpretability and assess the marginal effects of each covariate. There are other methods available to assess variable importance and marginal effects of covariates including SHAP plots, LIME plots, and global surrogates which were not explored in this paper [30]. Finally, it is important to be aware that random forests cannot perform extrapolation. While this is an advantage for a bounded outcome like hometime, as they will not generate implausible predictions, it can be a limitation if the range of outcome values in the test set is larger than that in the training set.

\section{Conclusion}

Random forests regression may be a useful analytic method for predicting 90-day hometime, a bounded variable with a highly non-normal distribution. The random forests regression model was able to capture complex non-linear relationships as well as interactions between many important covariates and hometime. Predictive 
accuracy was lowest for extreme values of hometime which may warrant future study. Future work should also focus on the comparison of random forests to other models.

\section{Abbreviations}

CART: Classification and regression tree; Bagging/ed: Bootstrap aggregation/ ed; CIHI: Canadian Institute for Health Information; DAD: Discharge Abstract Database; PaSSV: Passive Surveillance Stroke seVerity Indicator;

ED: Emergency department

\section{Supplementary Information}

The online version contains supplementary material available at https://doi. org/10.1186/s12874-021-01289-8.

Additional file 1: Table A.1. Administrative data comorbidity case definitions. Table A.2. Demographics of patients excluded due to privacy issues. Table A.3. Pairwise correlation of all covariates.

Figure A.1. Cohort selection. Figure 2. Random forests model residuals compared to actual 90-day hometime values.

\section{Acknowledgements}

This study contracted ICES Data \& Analytic Services (DAS) and used de-identified data from the ICES Data Repository, which is managed by ICES with support from its funders and partners: Canada's Strategy for Patient-Oriented Research (SPOR), the Ontario SPOR Support Unit, the Canadian Institutes of Health Research and the Government of Ontario. The opinions, results and conclusions reported are those of the authors. No endorsement by ICES or any of its funders or partners is intended or should be inferred. Parts of this material are based on data and information compiled and provided by $\mathrm{ClHI}$. However, the analyses, conclusions, opinions and statements expressed herein are those of the author, and not necessarily those of $\mathrm{ClHI}$.

\section{Authors' contributions}

JKH: Conceptualization, Methodology, Formal Analysis, Writing - Original Draft, Visualization. AYXY: Conceptualization, Funding Acquisition, Writing Review \& Editing. MKK: Conceptualization, Writing - Review \& Editing, Supervision. PCA: Conceptualization, Methodology, Writing - Review \& Editing, Supervision. All authors have read and approved the manuscript

\section{Funding}

This study was supported by the Canadian Institutes of Health Research Catalyst Grant 385156. The funders has no involvement in study design, data collection or analysis, interpretation or writing of the manuscript. JKH is supported by a Canadian Institutes of Health Research Fellowship. MKK and PCA are supported by Mid-Career Investigator Awards from the Heart and Stroke Foundation of Canada.

\section{Availability of data and materials}

The data sets used for this study were held securely in a linked, de-identified form and analyzed at ICES. While data sharing agreements prohibit ICES from making the data set publicly available, access may be granted to those who meet pre-specified criteria for confidential access, available at www.ices.on. $\mathrm{ca} / \mathrm{DAS}$.

\section{Declarations}

\section{Ethics approval and consent to participate}

This study was approved by the Sunnybrook Health Sciences Centre Research Ethics Board with waiver of consent. The use of data in this project was authorized under section 45 of Ontario's Personal Health Information Protection Act.

\section{Consent for publication}

N/A, no individual patient data are presented.

\section{Competing interests}

None.

\section{Author details}

'Department of Clinical Neurosciences, Cumming School of Medicine, University of Calgary, 3330 Hospital Drive NW, Calgary, AB T2N4N1, Canada. ${ }^{2}$ ICES, Toronto, ON, Canada. ${ }^{3}$ Department of Medicine (Neurology), University of Toronto, Sunnybrook Health Sciences Centre, Toronto, ON, Canada. ${ }^{4}$ Department of Medicine (General Internal Medicine), University of Toronto and University Health Network, Toronto, ON, Canada. ${ }^{5}$ nstitute of Health Policy, Management, and Evaluation, University of Toronto, Toronto, ON, Canada. ${ }^{6}$ Schulich Heart Research Program, Sunnybrook Research Institute, Toronto, ON, Canada.

Received: 6 July 2020 Accepted: 21 April 2021

Published online: 10 May 2021

\section{References}

1. Duncan PW, Jorgensen HS, Wade DT. Outcome measures in acute stroke trials: a systematic review and some recommendations to improve practice. Stroke. 2000;31(6):1429-38.

2. Quinn TJ, Dawson J, Lees JS, Chang TP, Walters MR, Lees KR, et al. Time spent at home poststroke: "home-time" a meaningful and robust outcome measure for stroke trials. Stroke. 2008;39(1):231-3.

3. Mishra NK, Shuaib A, Lyden P, Diener H-C, Grotta J, Davis S, et al. Home time is extended in patients with ischemic stroke who receive thrombolytic therapy: a validation study of home time as an outcome measure. Stroke. 2011;42(4):1046-50.

4. Campbell BCV, Mitchell PJ, Kleinig TJ, Dewey HM, Churilov L, Yassi N, et al. Endovascular therapy for ischemic stroke with perfusion-imaging selection. N Engl J Med. 2015;372(11):1009-18.

5. Fonarow GC, Liang L, Thomas L, Xian Y, Saver JL, Smith EE, et al. Assessment of home-time after acute ischemic stroke in Medicare beneficiaries. Stroke. 2016;47(3):836-42.

6. Yu AYX, Rogers E, Wang M, Sajobi TT, Coutts SB, Menon BK, et al. Population-based study of home-time by stroke type and correlation with modified Rankin score. Neurology. 2017;89(19):1970-6.

7. Stienen MN, Smoll NR, Fung C, Goldberg J, Bervini D, Maduri R, et al. HomeTime as a Surrogate Marker for Functional Outcome After Aneurysmal Subarachnoid Hemorrhage. Stroke. 2018;49(12):3081-4.

8. Hannah D, Lindholm B, Maisch L. Certain uncertainty: life after stroke from the patient's perspective. Circ Cardiovasc Qual Outcomes. 2014;7(6):968-9.

9. O'Brien EC, Xian Y, Fonarow GC, Olson DM, Schwamm LH, Hernandez AF. Clinical commentary on "certain uncertainty: life after stroke from the patient's perspective". Circ Cardiovasc Qual Outcomes. 2014 Nov;7(6):970.

10. Xian Y, O'Brien EC, Fonarow GC, Olson DM, Schwamm LH, Hannah D, et al. Patient-centered research into outcomes stroke patients prefer and effectiveness research: implementing the patient-driven research paradigm to aid decision making in stroke care. Am Heart J. 2015; 170(1):e1-11 36-45-45.

11. Yu AYX, Fang J, Kapral MK. One-Year Home-Time and Mortality After Thrombolysis Compared With Nontreated Patients in a Propensity-Matched Analysis. Stroke. 2019:STROKEAHA119026922.

12. O'Brien EC, Xian Y, Xu H, Wu J, Saver JL, Smith EE, et al. Hospital variation in home-time after acute ischemic stroke: insights from the PROSPER study (patient-centered research into outcomes stroke patients prefer and effectiveness research). Stroke. 2016;47(10):2627-33.

13. McDermid I, Barber M, Dennis M, Langhorne P, Macleod MJ, McAlpine CH, et al. Home-time is a feasible and valid stroke outcome measure in National Datasets. Stroke. 2019;50(5):1282-5.

14. Breiman L, Friedman J, Stone CJ, Olshen RA. Classification and regression trees. Boca Raton: Routledge; 1984. p. 1.

15. Breiman L. Random Forests. Machine Learn. 2001;45:5-32.

16. Hastie T, Tibshirani R, Friedman J. The Elements of Statistical Learning: Springer Science \& Business Media; 2013. p. 1.

17. James G, Witten D, Hastie T, Tibshirani R. An Introduction to Statistical Learning: Springer; 2014. p. 1.

18. Gilbert T, Neuburger J, Kraindler J, Keeble E, Smith P, Ariti C, et al. Development and validation of a hospital frailty risk score focusing on older people in acute care settings using electronic hospital records: an observational study. Lancet. 2018;391(10132):1775-82.

19. Yu AYX, Austin PC, Rashid M, Fang J, Porter J, Hill MD, et al. Deriving a passive surveillance stroke severity indicator from routinely collected 
administrative data: the passv indicator. Circ Cardiovasc Qual Outcomes. 2020;13:e006269.

20. Lipscombe LL, Hwee J, Webster L, Shah BR, Booth GL, Tu K. Identifying diabetes cases from administrative data: a population-based validation study. BMC Health Serv Res BioMed Central. 2018;18(1):316-8.

21. Hux JE, Ivis F, Flintoft V, Bica A. Diabetes in Ontario: determination of prevalence and incidence using a validated administrative data algorithm. Diabetes Care. 2002;25(3):512-6.

22. Tu K, Campbell NR, Chen Z-L, Cauch-Dudek K, McAlister FA. Accuracy of administrative databases in identifying patients with hypertension. Open Med. 2007;1(1):e18-26.

23. Tu K, Chen Z, Lipscombe LL. Canadian hypertension education program outcomes research taskforce. Prevalence and incidence of hypertension from 1995 to 2005: a population-based study. CMAJ. 2008;178(11):1429-35.

24. Austin PC, Daly PA, Tu JV. A multicenter study of the coding accuracy of hospital discharge administrative data for patients admitted to cardiac care units in Ontario. Am Heart J. 2002;144(2):290-6.

25. Juurlink D, Preyra C, Croxford R, Chong A, Austin PC, Tu JV, et al. Canadian Institute for Health Information Discharge Abstract Database: a validation study. Toronto: Institute for Clinical Evaluative Sciences; 2006.

26. Friedman J. Greedy function approximation: a gradient boosting machine. Ann Stat. 2001;29(5):1189-232.

27. Winovich DT, Longstreth WT, Arnold AM, Varadhan R, Zeki Al Hazzouri A, Cushman M, et al. Factors associated with ischemic stroke survival and recovery in older adults. Stroke. 2017;48(7):1818-26.

28. Goldstein LB, Samsa GP, Matchar DB, Horner RD. Charlson index comorbidity adjustment for ischemic stroke outcome studies. Stroke. 2004; 35(8):1941-5.

29. Falsetti L, Viticchi G, Tarquinio N, Silvestrini M, Capeci W, Catozzo V, et al. Charlson comorbidity index as a predictor of in-hospital death in acute ischemic stroke among very old patients: a single-cohort perspective study. Neurol Sci. 2016;37(9):1443-8.

30. Lundberg S, Lee S-I. A unified approach to interpreting model predictions. In: Luxburg von U, Bengio S, Fergus R, Garnett R, Guyon I, Wallach H, et al., editors. Advances in neural information processing systems 30. California: Long Beach; 2017. p. 4-9. 4766-75.

\section{Publisher's Note}

Springer Nature remains neutral with regard to jurisdictional claims in published maps and institutional affiliations.

Ready to submit your research? Choose BMC and benefit from:

- fast, convenient online submission

- thorough peer review by experienced researchers in your field

- rapid publication on acceptance

- support for research data, including large and complex data types

- gold Open Access which fosters wider collaboration and increased citations

- maximum visibility for your research: over $100 \mathrm{M}$ website views per year

At $\mathrm{BMC}$, research is always in progress.

Learn more biomedcentral.com/submissions 